\title{
Carinal resection and reconstruction with extracorporeal membrane oxygenation support
}

\author{
Francesco Petrella ${ }^{1,2}$, Lorenzo Spaggiari ${ }^{1,2}$ \\ ${ }^{1}$ Division of Thoracic Surgery, IRCCS European Institute of Oncology, Milan, Italy; ${ }^{2}$ Department of Oncology and Hemato-oncology, University of \\ Milan, Milan, Italy \\ Contributions: (I) Conception and design: All authors; (II) Administrative support: All authors; (III) Provision of study materials or patients: All \\ authors; (IV) Collection and assembly of data: All authors; (V) Data analysis and interpretation: All authors; (VI) Manuscript writing: All authors; (VII) \\ Final approval of manuscript: All authors. \\ Correspondence to: Prof. Francesco Petrella, MD, PhD. Department of Thoracic Surgery, IRCCS European Institute of Oncology, Milan, Italy; \\ Department of Oncology and Hemato-oncology, University of Milan, Milan, Italy; Via Ripamonti 435, 20141 Milan, Italy. \\ Email: francesco.petrella@ieo.it; francesco.petrella@unimi.it.
}

\begin{abstract}
Resection of the main carina is one of the most complex procedures of airway resection and reconstruction. It is defined as the resection of the tracheo-bronchial bifurcation and can be accomplished with or without pulmonary resection. Carinal pneumonectomy is defined as the removal of the whole lung together with the main carina; it is usually performed on the right side while it is quite uncommon on the opposite side, although feasible in selected cases. The most frequent indication for carinal pneumonectomy (CP) is primary lung cancer with involvement of the carina or the distal trachea. Isolated carinal resection (CR) without pulmonary resection is rarer and it is performed in patients with primary tumors of the distal tract of the trachea or the carinal bifurcation. Cross-field ventilation (CFV) usually provides adequate support to guarantee tissue oxygenation after tracheal transection; however, airway reconstruction can sometimes be very difficult because of the presence of the ventilation tube in the bronchus to be anastomosed. Extracorporeal membrane oxygenation (ECMO) is a cardio-pulmonary system providing cardiac, pulmonary and circulatory support in the case of cardiac and/or respiratory failure. It can temporarily support cardiac and pulmonary functions until they are restored or-in more advanced cases of pulmonary failure-until lung transplant. The veno-venous ECMO (VV ECMO) is an effective alternative to CFV, allowing tissue oxygenation and $\mathrm{CO}_{2}$ extraction without the need for tubes in the surgical field. Care should be taken when cannulating vessels as well as managing the ECMO flow during the procedure, in order to prevent major complications. In this paper we focus on the more common techniques of CR and the role of the VV ECMO during the procedure.
\end{abstract}

Keywords: Extracorporeal membrane oxygenation (ECMO); tracheal sleeve pneumonectomy; carinal resection

Received: 28 April 2020; Accepted: 02 July 2020; Published: 25 August 2021.

doi: $10.21037 /$ ccts-20-91

View this article at: http://dx.doi.org/10.21037/ccts-20-91

\section{Introduction}

Resection of the main carina is one of the most complex procedures of airway resection and reconstruction. It is defined as the resection of the tracheo-bronchial bifurcation and can be accomplished with or without pulmonary resection (1).
Carinal pneumonectomy (CP) is defined as the removal of the whole lung together with the main carina; it is usually performed on the right side while it is quite uncommon on the opposite side, although feasible in selected cases. The most frequent indication for $\mathrm{CP}$ is primary lung cancer with involvement of the carina or the distal trachea. Isolated carinal resection (CR) without pulmonary resection is rarer 
and it is performed in patients with primary tumors of the distal tract of the trachea or the carinal bifurcation (2).

One of the most difficult aspects of CR and reconstruction-both in cases of $\mathrm{CP}$ and $\mathrm{CR}$-is providing adequate ventilation during tracheal transection. Crossfield ventilation (CFV) is usually used to overcome this aspect: the main bronchus of the remaining lung, in the case of CP, or one of the two lungs, in the case of CR, is directly intubated by the surgeon from the surgical field; sometimes jet ventilation can be added. Although this is an effective and well-established technique, it makes bronchial reconstruction quite difficult because of the presence of the tube in the bronchus and the continuous need for ventilation during the anastomotic phase (3). An adequate alternative strategy for providing adequate ventilation while performing the anastomosis is the use of the extracorporeal membrane oxygenation (ECMO). This is a cardiocirculatory and pulmonary support providing extracorporeal circulation by using centrifugal pumps and oxygenators to enrich $\mathrm{O}_{2}$ and eliminate $\mathrm{CO}_{2}(4)$.

In this review we focus on the intraoperative role of ECMO during CR.

\section{History}

The first experimental attempts of tracheo-carinal resections started in the 1940s: the first experiments on dogs were reported in 1949 by Grindlay et al. who performed a right $\mathrm{CP}$ and airway reconstruction by an end-to-end anastomosis between the distal trachea and the left main bronchus (5). Juvenelle and Citret described implant of the main bronchus (both right and left) on the lateral wall of the trachea following limited tracheal resection (6).

The first clinical experience in 1950 was reported by Abbott who repaired a major tracheal defect by transverse closure following extended right pneumonectomy (7); in 1951, Mathey first described the resection of a cylindroma of the main carina and its reconstruction by longitudinal suturing (8). Crafoord et al. reported airway reconstruction after right upper tracheal lobectomy by anastomosing the bronchus intermedius to the trachea, in 1954 (9).

In 1955, Bjork described left main bronchus resection, after aorta mobilization, and direct anastomosis of the left bronchial bifurcation to the distal trachea (10). In 1957, Barclay described a tracheo-carinal resection to resect an adenoid cystic carcinoma; airway reconstruction was accomplished by anastomosing end-to-end the distal trachea to the right main bronchus and the left main bronchus to the bronchus intermedius by an end-to-side anastomosis (11).

In 1963, Grillo described a different technique for airway reconstruction following the same type of resection: he anastomosed the distal trachea to the right main bronchus by an end-to-end anastomosis; the left main bronchus was reconnected to the trachea by an end-to-side anastomosis (12). In 1961, Woods first reported the use of cardiopulmonary bypass (CBP) for airway reconstruction following carina resection for cylindroma (13).

In 1967, Eschapasse et al. described three consecutive cases of main carina resection whose reconstruction was performed, in two cases, by an end-to-end anastomosis between the right main bronchus and trachea and an endto-side anastomosis between the left main bronchus and bronchus intermedius. In the other case, an end-to-end anastomosis between the trachea and left main bronchus and an end-to-side anastomosis between the intermediate bronchus and the left main bronchus were performed (14).

More recently, thanks to regenerative medicine developments, bioengineering and stem cell technology were involved in the reconstructive part of carinal surgery: in 2004, Klepetko et al. described a heterotopic transplantation of the trachea together with omentum wrapping in the abdomen (15). In 2008, Macchiarini et al. described the first tracheal transplantation by replacing the left main bronchus of a patient suffering from tuberculosis with a stem cell-engineered human trachea (16); however, after initial enthusiasms, this technique did not appear feasible and safe and was thus abandoned (17).

\section{Surgical procedures}

\section{CR without pulmonary resection}

\section{Neocarina}

This is a resection technique to remove only the main carina, preserving the whole lung parenchyma bilaterally (Figure 1A). It is indicated only in the case of pure and small carinal tumors, without full main bronchi involvement. Airway reconstruction is provided by anastomosing the medial aspects of both main bronchi that are subsequently sutured to the distal trachea (Figure 1B). The most difficult part is the mobilization of the left main bronchi under the aortic arch. This is performed by median sternotomy with transpericardial approach (18).

\section{Barclay}

This is indicated when a longer tract of the trachea together 
A

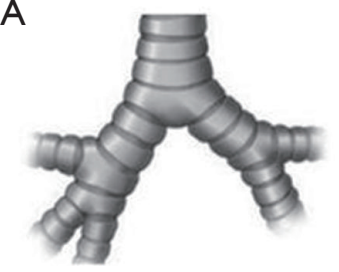

Normal anatomy

E

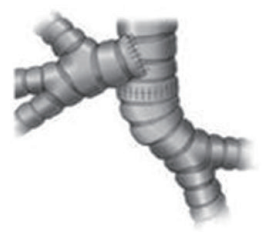

Eschapasse (reverse Gillo)

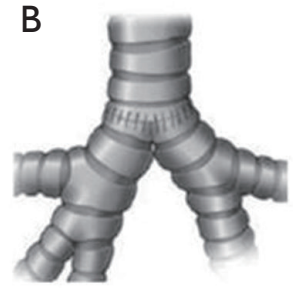

Neocarina

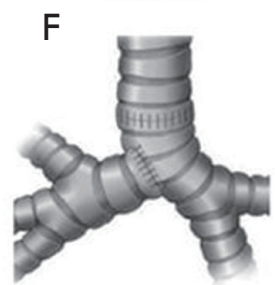

Eschapasse (reverse Barclay)

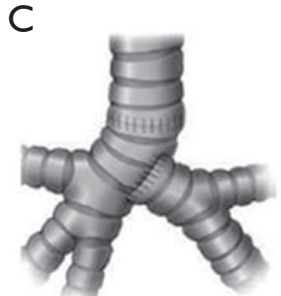

Barclay

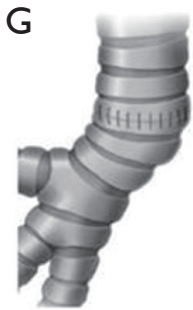

Left carinal pneumonectomy

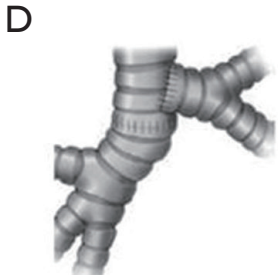

Grillo

$\mathrm{H}$

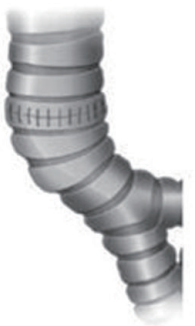

Right carinal pneumonectomy

Figure 1 Classification of carinal resections. (A) Normal anatomy of the main carina; (B) Neocarina; (C) Barclay; (D) Grillo; (E) Eschapasse (reverse Grillo); (F) Eschapasse (reverse Barclay); (G) left carinal pneumonectomy; (H) right carinal pneumonectomy.

with the main carina needs to be resected. After tracheacarinal resection, airway reconstruction is obtained first by anastomosing end-to-end the distal remaining trachea to the right main bronchus; the left main bronchus is then anastomosed-by an end-to-side anastomosis-on the lateral aspect of the bronchus intermedius where an ovoid opening has been previously obtained (18) (Figure 1C). It may be really difficult to perform the second anastomosis with CFV; veno-venous ECMO (VV ECMO) support is an ideal and effective alternative for providing tissue oxygenation without any disturbing lines or tubes in the surgical field (2). It is performed by median sternotomy with transpericardial approach.

\section{Grillo}

This procedure is very similar to the Barclay technique; in this case airway reconstruction is obtained by anastomosing end-to-end the remaining distal trachea to the right main bronchus; the left main bronchus is then anastomosed to the lateral aspect of the trachea where an ovoid opening has been previously obtained (18) (Figure 1D). As with the Barclay technique, the second anastomosis can be very difficult, particularly in the case of CFV; VV ECMO support is an excellent oxygenation strategy during this procedure (2). It is performed by median sternotomy with transpericardial approach.

\section{Eschapasse}

After completing the tracheo-carinal resection, airway reconstruction is obtained by anastomosing first the distal trachea to the left main bronchus. The right main bronchus is then anastomosed by an end-to-side anastomosis to the lateral aspect of the tracheal wall (reverse Grillo technique) (Figure 1E) or, more rarely, to the medial wall of the left main bronchus where an ovoid opening has been previously performed (reverse Barclay technique) (18) (Figure 1F). As with the Grillo and the Barclay techniques, VV ECMO is an effective oxygenation strategy during this operation (2). It is performed by median sternotomy with transpericardial approach.

\section{CR with pulmonary resection}

\section{Left carinal pneumonectomy}

In this procedure, the standard approach is left thoracotomy if no more than one centimeter of the distal trachea and right main bronchus have to be resected; median sternotomy is mandatory when a longer section of the distal trachea needs to be resected.

Deep isolation beneath the aortic arch is performed, taking care not to injury the left laryngeal nerve, whenever possible; to maximize carinal exposure from the left side, Botallo's ligament has to be transected and the aortic arch 


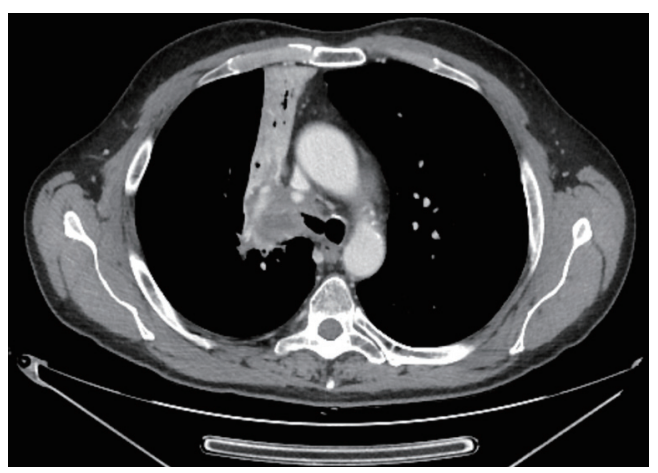

Figure 2 Computed tomography disclosing carinal infiltration from primary lung cancer of the right main bronchus, requiring right carinal pneumonectomy.

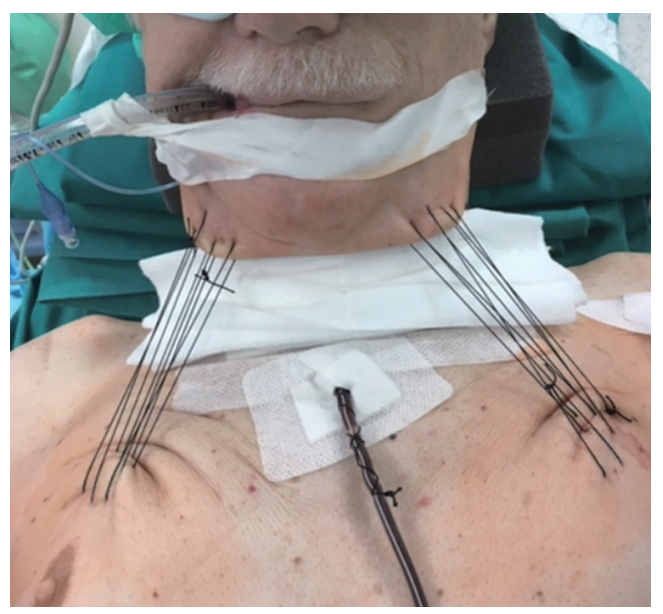

Figure 3 Neck flexion is recommended for a week after the procedure by stitches applied between chin and presternal tissue. This image is published with the patient's permission.

needs to be gently retracted.

Pulmonary artery and veins are divided, the distal trachea and the left main bronchus are transected first; the right main bronchus is transected last. The anastomosis is then performed between the distal trachea and right main bronchus where the ventilation tube is placed in case of CFV (Figure 1G); due to the unfavorable surgical field, ECMO support is strongly recommended during the reconstructive phase of this operation (2).

\section{Right carinal pneumonectomy}

It is usually performed by right thoracotomy; care must be taken when encircling the distal trachea to avoid left laryngeal nerve damage. The left main bronchus is transected first and then the distal trachea. When CP is performed by $\mathrm{CFV}$, at this point the left main bronchus is intubated from the surgical field and adequate ventilation is provided to the left lung. The distal trachea and the left main bronchus are anastomosed with the ventilation tube still inside the left main bronchus (Figure 1H); this part of the procedure can therefore be challenging and $\mathrm{VV}$ ECMO support allows tracheo-bronchial anastomosis to be performed without any interfering tubes in the surgical field. After completing the anastomosis, several more stitches are required to obtain a tension-free anastomosis; a pedicled fat flap is also recommended to separate vascular and bronchial structures in order to prevent catastrophic bronchovascular fistula (19). This procedure is indicated when no more than four centimeters of the trachea need to be removed (Figure 2). In every case of CR and reconstruction, with or without pulmonary resection, we recommend neck flexion for a week after the procedure by applying stitches between chin and presternal tissue (Figure 3).

\section{ECMO-assisted CR}

ECMO is a cardio-pulmonary system providing cardiac, pulmonary and circulatory support in the case of cardiac and/or respiratory failure. It can temporarily support cardiac and pulmonary functions until they are restored or, in more advanced cases of pulmonary failure, until lung transplant (20). Indications for ECMO in general thoracic, non-cardiac, surgery, is usually limited to postpneumonectomy acute respiratory distress syndrome (ARDS), pediatric surgery for tracheobronchial congenital disorders and lung transplants (21).

ECMO allows extra-corporeal circulation; its basic tools are the oxygenator-providing blood oxygenation and $\mathrm{CO}_{2}$ removal-and non-occlusive centrifugal pumps to replace cardiac function.

According to site and type of vessel cannulation, ECMO can be peripheral or central, offering partial or complete cardio-circulatory support; veno-arterial ECMO (VA ECMO), supporting both cardiac and pulmonary function, and VV ECMO, replacing only respiratory function allowing blood enrichment of $\mathrm{O}_{2}$ and $\mathrm{CO}_{2}$ removal, are also possible (22).

VV ECMO is the preferred choice for supporting respiratory function during CR; cardiac instability should therefore be excluded before surgery. Jugulo-femoral or femoro-jugular cannulations are the most frequently used techniques in this setting; however, femoro-femoro 
cannulation or solely jugular cannulation by double lumen single cannula can be considered; as arterial cannulation is not required, vascular complications related to cannulations technique are quite uncommon. Our favourite cannulation is jugulo-femoral cannulation which resulted always effective except one case that required central atrial cannulation.

ECMO handling appears superior to standard CBP for CR: in fact, it requires lower anticoagulation times and lower doses of heparin at cannulation, thus reducing the risk of intra and post-operative major bleeding, particularly in the case of CP. The ECMO support during CR is usually limited to the reconstructive phase-usually shorter than half an hour-thus further reducing the risk of pulmonary embolism.

The major advantage of intraoperative ECMO support during $\mathrm{CR}$ and reconstruction is avoiding the need for CFV thus allowing easier and faster anastomosis; moreover, if safe extubation is not possible at the end of the procedure, peripheral ECMO can be prolonged during intensive care stay. On the other hand, a higher risk of postoperative haemothorax should be taken into account, as well as potential vascular complication related to cannulation. Although doubts about neoplastic cell seeding during ECMO in neoplastic patients have been reported in the past (23), there are no clear data supporting the theoretical risk of neoplastic cell scattering; nevertheless, we recommend starting VV-ECMO only after closure of pulmonary artery and veins, limiting its support to just the airway reconstruction phase. To further investigate the potential impact of ECMO on tumor spreading, a prospective, doublearm, observational study is on-going in our department, comparing the number of circulating tumor cells (CTC) before and after the resection-in patients belonging to the same stages—operated with or without ECMO (24).

ECMO blood flow during CR should provide arterial oxygenation ranging at least between $85 \%$ and $95 \%$; lower values, due to a low ECMO circuit flow, may result in severe brain and coronary ischemic injuries (25).

In the case of $\mathrm{AV} \mathrm{ECMO}$, adequate cannula positioning is extremely important to prevent the so-called "Harlequin syndrome" that may be observed if the tips of the cannulas are too close to each other: in this case, in fact, the oxygenated blood goes directly to the tip of the draining cannula instead of reaching the pulmonary artery. As consequence, there is a "recirculation" effect with impaired perfusion of the upper body, resulting in ischemia of the heart and brain and cyanosis of the upper extremities. In this case, the arterial cannula needs to be rapidly repositioned within the aorta or the subclavian artery (26).

In our experience, from November 2018 to November 2019, we performed six ECMO-assisted tracheal sleeve pneumonectomies for non-small cell lung cancer; median operatory time was 201 minutes (range, 162-292 minutes), and mean duration of VV-ECMO was 38 minutes (range, 31-45 minutes). We had one case of post operative haemothorax. At the time of follow-up, 5 patients were alive with non-evident disease (NED) and one was alive with disease (AWD) presenting bone metastasis treated by radiation therapy (27).

\section{Conclusions}

CR is a challenging procedure in thoracic surgery; there are several different techniques for airway reconstruction depending on the localization of the tumor and its extension. CFV usually provides adequate support to guarantee tissue oxygenation after tracheal transection; however, airway reconstruction can sometimes be very difficult because of the presence of the ventilation tube in the bronchus to be anastomosed.

$\mathrm{VV}$-ECMO is an effective alternative to $\mathrm{CFV}$, allowing tissue oxygenation and $\mathrm{CO}_{2}$ extraction without the need for tubes in the surgical field. Care should be taken when cannulating vessels and in managing the ECMO flow during the procedure, in order to prevent major complications.

ECMO-assisted CR should be performed by multidisciplinary teams with high-volume experience both in oncologic thoracic surgery and mechanical cardiorespiratory support.

\section{Acknowledgments}

Funding: This work was partially supported by the Italian Ministry of Health with 'Ricerca Corrente' and ' $5 \times 1000$ ' funds.

\section{Footnote}

Provenance and Peer Review: This article was commissioned by the Guest Editors (Andrea Dell'Amore and Nizar Asadi) for the series "Mechanical Extracorporeal CardioRespiratory Supports in General Thoracic Surgery" published in Current Challenges in Thoracic Surgery. The article has undergone external peer review.

Conflicts of Interest: Both authors have completed the 
ICMJE uniform disclosure form (available at https://ccts. amegroups.com/article/view/10.21037/ccts-20-91/coif). The series "Mechanical Extracorporeal Cardio-Respiratory Supports in General Thoracic Surgery" was commissioned by the editorial office without any funding or sponsorship. FP serves as an unpaid editorial board member of Current Challenges in Thoracic Surgery from January 2020 to December 2021. The authors have no other conflicts of interest to declare.

Ethical Statement: The authors are accountable for all aspects of the work in ensuring that questions related to the accuracy or integrity of any part of the work are appropriately investigated and resolved. Written informed consent was obtained from the patient for publication of this study and any accompanying images.

Open Access Statement: This is an Open Access article distributed in accordance with the Creative Commons Attribution-NonCommercial-NoDerivs 4.0 International License (CC BY-NC-ND 4.0), which permits the noncommercial replication and distribution of the article with the strict proviso that no changes or edits are made and the original work is properly cited (including links to both the formal publication through the relevant DOI and the license). See: https://creativecommons.org/licenses/by-nc-nd/4.0/.

\section{References}

1. Spaggiari L, Petrella F, Galetta D. Carinal resection. Multimed Man Cardiothorac Surg 2012;2012:mms001.

2. Petrella F, Salvi L, Venturino M, et al. Veno-venous extracorporeal membrane oxygenation tracheal sleeve pneumonectomy. Shanghai Chest 2020;4:7.

3. Porhanov VA, Poliakov IS, Selvaschuk AP, et al. Indications and results of sleeve carinal resection. Eur J Cardiothorac Surg 2002;22:685-94.

4. Rosskopfova P, Perentes JY, Ris HB, et al. Extracorporeal support for pulmonary resection: current indications and results. World J Surg Oncol 2016;14:25.

5. Grindlay JH, Clagett OT, Moersch HJ. Experimental surgery of the thoracic trachea and its bifurcation; preliminary report. Proc Staff Meet Mayo Clin $1949 ; 24: 555$.

6. Juvenelle AA, Citret C. Transplantation de la bronche souche et résection de la bifurcation trachéale. Une étude expérimentale sur le chien. J Chir 1951;67:666-88.

7. Abbott OA. Experiences with the surgical resection of the human carina, tracheal wall and contralateral bronchial wall in cases of right total pneumonectomy. J Thorac Surg 1950;19:906-22.

8. Mathey J. Tumeur bénigne de l'éperon Trachéal. Résection et Réfection du carrefour trachéo-bronchique. La Sem des Hopitaux Paris 1951;27:2699-703.

9. Crafoord C, Bjork VO, Hilty H. Bronchial resection and broncho-tracheal anastomosis in tuberculous bronchial stenosis; report of a case. Thoraxchirurgie 1954;2:1-7.

10. Bjork VO. Left sided bronchial anastomosis. J Thorac Surg 1955;30:492-8.

11. Barclay RS, McSwan N, Welsh TM. Tracheal reconstruction without the use of grafts. Thorax 1957;12:177-80.

12. Grillo HC, Bendixen HH, Gephart T. Resection of the carina and lower trachea. Ann Surg 1963;158:889-93.

13. Woods FM, Neptune WB, Palatichi A. Resection of the carina and mainstem bronchi with the use of extracorporeal circulation. N Engl J Med 1961;264:492-4.

14. Eschapasse H, Vahdat F, Gaillard J, et al. Reflections on resection of the lower trachea and bronchial bifurcation. Ann Chir Thorac Cardiovasc 1967;6:63-70.

15. Klepetko W, Marta GM, Wisser W, et al. Heterotopic tracheal transplantation with omentum wrapping in the abdominal position preserves functional and structural integrity of a human tracheal allograft. J Thorac Cardiovasc Surg 2004;127:862-7.

16. Macchiarini $P$, Jungebluth $P$, Go $T$, et al. Clinical transplantation of a tissue-engineered airway. Lancet 2008;372:2023-30.

17. Else H. Scandal-weary Swedish government takes over research-fraud investigations. Nature 2019;571:158.

18. de Perrot M, Fadel E, Dartevelle P. Carinal resection. In: Patterson GA, Cooper JD, Deslauriers J, et al. editors. Pearsons's Thoracic and Esophageal Surgery, 3rd edn. Churchill, PA: Livingstone Elsevier, 2008:383-92.

19. Weder W, Inci I. Carinal resection and sleeve pneumonectomy. Thorac Surg Clin 2014;24:77-83.

20. Aigner C, Wisser W, Taghavi S, et al. Institutional experience with extracorporeal membrane oxygenation in lung transplantation. Eur J Cardiothorac Surg 2007;31:468-73; discussion 473-4.

21. Abrams D, Combes A, Brodie D. Extracorporeal membrane oxygenation in cardiopulmonary disease in adults. J Am Coll Cardiol 2014;63:2769-78.

22. Voelckel W, Wenzel V, Rieger M, et al. Temporary extracorporeal membrane oxygenation in the treatment of acute traumatic lung injury. Can J Anaesth 1998;45:1097-102. 
23. Brutel de la Rivière A, Knaepen P, Van Swieten H, et al. Concomitant open heart surgery and pulmonary resection for lung cancer. Eur J Cardiothorac Surg 1995;9:310-3; discussion 313-4.

24. Petrella F (Principal Investigator). Circulating Tumor Cells (CTC) Before and After Thoracic Resection With and Without Intraoperative Use of ExtraCorporeal Membrane Oxygenator (ECMO) or Cardio Pulmonary By Pass (CPB). Available online: https://clinicaltrials.gov/ct2/ show/NCT04048512? term=CTC\%2C+ECMO\&rank=1 .

doi: $10.21037 /$ ccts-20-91

Cite this article as: Petrella F, Spaggiari L. Carinal resection and reconstruction with extracorporeal membrane oxygenation support. Curr Chall Thorac Surg 2021;3:28.
Last accessed Apr, 2020.

25. Smith IJ, Sidebotham DA, McGeorge AD. Use of Extracorporeal Membrane Oxygenation during Resection of Tracheal Papillomatosis. Anesthesiology 2009;110:427-9.

26. Rupprecht L, Lunz D, Philipp A, et al. Pitfalls in percutaneous ECMO cannulation. Heart Lung Vessel 2015;7:320-6.

27. Spaggiari L, Sedda G, Petrella F, et al. Preliminary results of ECMO-Assisted Tracheal Sleeve Pneumonectomy for Cancer. Thorac Cardiovasc Surg 2020. (In Press). 